\title{
Postural Orthostatic Tachycardia Syndrome in Pediatric Patients with Celiac Disease and Relationship with Tissue Transglutaminase Antibody Levels and HLA Tissue Group
}

\author{
Elif Erolu ${ }^{1}$, $\odot$ Esra Polat ${ }^{2}$
}

${ }^{1}$ Department of Pediatric Cardiology, University of Health Sciences Turkey, Umraniye Health Aplication and Research Center, Istanbul, Turkey ${ }^{2}$ Department of Pediatric Gastroenterology, University of Health Sciences Turkey, Sancaktepe Prof. Dr. Ilhan Varank Health Aplication and Research Center, Istanbul, Turkey

\begin{abstract}
Introduction: Celiac disease is an autoimmune disease triggered by gluten in cereals. Many other system involvements may occur in Celiac disease. One of them is the autonomic nervous system. The role of autoimmunity in the etiology of postural orthostatic tachycardia syndrome (POTS) is also discussed recently. In this study, we aimed to investigate the presence of POTS and its relationship with serum antibody levels and HLA tissue group in patients with newly diagnosed Celiac disease and gluten-free diet not yet started.

Methods: Active standing test was applied to patients with the Celiac disease with orthostatic symptoms. POTS diagnosis was made for those who had orthostatic complaints for six months and who were found to be positive for the active standing test and who have not systemic disease and anemia.

Results: POTS positivity was found in 16 patients (34\%) out of 47 patients who met the inclusion criteria. In POTS positive patients, female gender (62.5\%) was higher than male gender (37.5) $(p=0.023)$. POTS was positive in $13(41 \%)$ of 31 patients with anti-Tg IgA levels above $200 \mathrm{U} / \mathrm{ml}$ and POTS positive in three (18\%) of 16 patients with anti-Tg lgA levels below $200 \mathrm{U} /$ $\mathrm{ml}(\mathrm{p}=0.04)$. Twenty-one patients had HLADQ2, four patients had HLADQ8, 15 patients had HLADQ2 and HLADQ8 positivity. Out of the 15 patients who were found to be HLADQ2 and HLADQ8 positive, nine patients (65\%) were POTS positive, out of the 21 patients who were found to be HLADQ2 positive, seven patients had POTS positivity (33\%) $(p=0.04)$.

Discussion and Conclusion: In our study, we showed that POTS frequency increased with an increase in the Anti-Tg IgA level and HLADQ2 and DQ8 association. This supports that POTS is an autoimmune disease. The presence of POTS should be kept in mind in the presence of orthostatic symptoms in pediatric celiac disease.

Keywords: Anti-Tg IgA; celiac disease; HLA; postural orthostatic tachycardia syndrome.
\end{abstract}

C eliac disease (CD) is an autoimmune enteropathy that occurs in the presence of genetic predisposition against gluten and gluten-related prolamines found in grains, such as wheat, rye, barley ${ }^{[1]}$. Although its true prevalence is not known exactly, in a screening study all over Turkey performed by Dalgıç et al., ${ }^{[2]}$ serological posi- tivity rates were reported as $1 / 94$, and biopsy-proven celiac disease was reported as $1 / 212$ in the 6-17 age range. Malabsorption, which is characteristic of $C D$, and related gastrointestinal symptoms are well-defined. Due to the underlying autoimmunity in $C D$, intestinal system involvement and related symptoms can also be seen ${ }^{[3]}$. The mode of the

Correspondence (iletişim): Elif Erolu, M.D. Saglik Bilimleri Universitesi Umraniye Saglik Uygulama ve Arastirma Merkezi, Pediatrik Kardiyoloji Anabilim Dali, Istanbul, Turkey

Phone (Telefon): +90 2165458677 E-mail (E-posta): eliferolu@yahoo.com

Submitted Date (Başvuru Tarihi): 26.01.2020 Accepted Date (Kabul Tarihi): 02.03.2020

Copyright 2020 Haydarpaşa Numune Medical Journal

OPEN ACCESS This is an open access article under the CC BY-NC license (http://creativecommons.org/licenses/by-nc/4.0/). 
emergence of CD has changed over the years, besides the typical symptoms associated with malabsorption, findings not related to the gastrointestinal system have also become more common in the course of the disease ${ }^{[4]}$. Articles about autonomic nervous system involvement in $C D$ are limited in number. In the literature, there is only one study evaluating autonomic dysfunction in pediatric Celiac patients $^{[5]}$. Postural orthostatic tachycardia (POTS) is an indicator of autonomic dysfunction. In our study, the relationship between postural orthostatic tachycardia (POTS) and tissue group, tissue transglutaminase IgA levels were evaluated in pediatric newly diagnosed $C D$ patients who had not yet started a gluten-free diet (GFD).

\section{Materials and Methods}

Fifty-eight patients ( 24 boys, 34 girls) who were diagnosed with CD based on esophagogastroduodenoscopic and histopathological evaluation and had not yet started a gluten-free diet (GFD) were included in this study. All patients were evaluated by 12-lead electrocardiography and echocardiography. The criteria for exclusion from this study were the use of medication, the presence of anemia, thyroid dysfunction, rhythm disturbance, additional systemic or cardiac disease, presence of orthostatic hypotension (low blood pressure in the standing systolic BP/diastolic BP more than $20 / 10 \mathrm{mmHg}$ ), failure to meet diagnostic criteria of POTS. Patients with hypothyroidism $(n=3)$, diabetes mellitus $(n=2)$, Down syndrome and VSD $(n=2)$, and those with serum $\mathrm{Hb}$ levels below $10 \mathrm{~g} / \mathrm{dl}(\mathrm{n}=4)$ were excluded from this study.

Forty-seven patients included in this study were grouped according to their tissue groups (HLA-DQ2, HLA-DQ8), histopathological staging and tissue transglutaminase $\lg A$ (Anti-Tg $\lg A$ ) levels. Among these patients, 28 patients with orthostatic symptoms, such as palpitations, chest pain or discomfort, dizziness, blurred vision, shortness of breath, headache, nausea, and fatigue, were applied for the last isx months underwent the active standing test.

Blood pressure was measured in a horizontal position and standing position with an automatic sphygmomanometer. After resting for five minutes in the supine position, patients were evaluated at $0,1,3,5,10$ minutes while standing, synchronized with electrocardiographic monitoring of heart rate.

When changing from horizontal position to vertical position, the test was considered positive if the heart rate increased $40 /$ minute or the heart rate exceeded 120/minute within the first 10 minutes without any drop in systolic/diastolic blood pressure more than $20 / 10 \mathrm{mmHg}^{[6]}$. In the last six months, patients with orthostatic symptoms, without orthostatic hypotension (blood pressure dropping more than $20 / 10 \mathrm{mmHg}$ in standing position) and meeting the criteria for POTS with the active standing test were diagnosed as POTS ${ }^{[7]}$. Informed consent was obtained from all patients. This study was approved by the ethics committee of Ümraniye Training and Research Hospital.

\section{Statistical Analysis}

SPSS 22 software package (IBM Corp., Armonk, NY, USA) was used for statistical analysis. Kolmogorov- Smirnov test was used to determine the normality of distribution. Data were expressed as numbers and percentages (\%). A Chisquare test was used to compare the groups. $\mathrm{P}<0.05$ was accepted as the level for statistical significance.

\section{Results}

POTS positivity was detected in 16 (34\%) out of 47 patients included in this study. The mean age of the patients was 14.3 \pm 2.8 . Among POTS- positive cases, female patients $(10 / 16 ; 62.5 \%)$ were greater in number than male patients $(6 / 16 ; 37.5)(p=0.023)$. POTS positivity was detected in 13 (41\%) of 31 patients with anti-Tg IgA levels above $200 \mathrm{U} /$ $\mathrm{ml}$ and in three (18\%) of 16 patients with anti-Tg IgA levels below $200 \mathrm{U} / \mathrm{ml}$. The frequency of POTS was found to be increased in patients with anti-Tg lgA levels above $200 \mathrm{U} /$ $\mathrm{ml}(\mathrm{p}=0.04)$.

A positive correlation was found between the anti-Tg $\lg A$ levels and the heart rate at the $2 \mathrm{nd}$ and 5 th minutes of the tests in POTS- positive patients $(r=0.62, p=0.001 ; r=0.60$, $\mathrm{p}=0.001$ ). Twenty-one patients had HLADQ2, four patients had HLADQ8, 15 patients had HLADQ2 and HLADQ8- positivity. HLA tissue results of seven patients could not be obtained. Out of the15 patients who were found to be HLADQ2 and HLADQ8 positive, nine patients (65\%) were POTS positive, out of the 21 patients who were found to be HLADQ2 positive, seven patients had POTS positivity (33\%) $(p=0.04)$ (Table 1).

Table 1. Number of POTS positive and POTS negative patients and distribution of the patient numbers according to HLA tissue groups and levels of Anti-Tg $\lg \mathrm{A}$

\begin{tabular}{lcc}
\hline & POTS (+) & POTS (-) \\
\hline Anti-Tg lgA $<200 \mathrm{U} / \mathrm{ml}, \%$ & $3 / 16(18)$ & $13 / 16(81)$ \\
AntiTgA $>200 \mathrm{U} / \mathrm{ml}, \%$ & $13 / 31(41)$ & $18 / 31(19)$ \\
HLADQ2, \% & $7 / 21(33)$ & $14 / 21(67)$ \\
HLADQ8, \% & $1 / 4(25)$ & $3 / 4(75)$ \\
HLADQ2+8, \% & $9 / 15(65)$ & $6 / 15(35)$ \\
\hline
\end{tabular}




\section{Discussion}

POTS represents a common form of orthostatic intolerance. POTS is an autonomic nervous system disease with orthostatic intolerance symptoms, such as orthostatic tachycardia, dizziness, palpitation and non-orthostatic symptoms such as fatigue, myofascial pain, nausea, migraine and headache ${ }^{[8]}$. The frequency of POTS is $0.2 \%$ and its incidence is higher in women ${ }^{[9]}$.

While normally, in a standing position, venous collection in the lower extremity and gravity effect decreases venous return to the heart due to fluid transfer to the interstitial space. Cardiac filling and stroke volume decrease, and blood pressure decrease. The autonomic nervous system tries to compensate by increasing sympathetic activity on the heart and blood vessels and decreasing parasympathetic activity. Heart rate and systemic vascular resistance are increased; the initial drop in blood pressure is normalized.

With these compensatory mechanisms, an increase of 10-20 bpm in peak heart rate and a negligible increase in systolic and diastolic blood pressures occur. The necessary hemodynamic compensation does not occur in the presence of autonomic dysfunction. In the presence of orthostatic symptoms, a detailed history should be taken from the patient and the use of medication should be questioned. Since congenital heart disease, thyroid dysfunction, arrhythmia, and anemia may also cause orthostatic symptoms, they should be excluded before the diagnosis of POTS was made.

It has been reported that celiac patients often have extraintestinal symptoms, such as palpitations, dizziness and presyncope, which may be associated with the autonomic nervous system ${ }^{[10,11]}$. In contrast, in patients diagnosed with POTS, symptoms related to the gastrointestinal tract, such as nausea, bloating, abdominal pain, constipation and diarrhea outside the cardiovascular system, have been identified at a rate of $15-40 \%{ }^{[8,12]}$. Autonomic system dysfunction most likely underlies these complaints concerning the gastrointestinal tract.

Patients with the diagnosis of POTS reported having complaints with gluten intake. In addition, the frequency of biopsy-proven celiac disease was found to be increased in patients with POTS compared to the normal population ${ }^{[13]}$. POTS, which has many pathophysiological mechanisms, is thought to have an autoimmune etiology in recent years ${ }^{[14,15]}$. It has been found that many autoimmune diseases, such as rheumatoid arthritis, Sjogren's syndrome, Hashimoto's thyroiditis, and antiphospholipid syndrome, may develop before or after the diagnosis of POTS ${ }^{[16]}$. Antibodies, such as ANA, atypical ANCA, antiphospholipid antibody, Sjögren antibody, which are autoimmunity markers, were found to be increased in POTS patients compared to the general population ${ }^{[16]}$. In our study, the frequency of POTS was significantly higher in patients with Anti-Tg IgA levels above $200 \mathrm{U} / \mathrm{ml}$. This finding shows that autoimmunity may play a role in the mechanism of POTS.

The incidence of autoimmune diseases in HLADQ2- positivity has increased compared to the normal population ${ }^{[14,17]}$. The coexistence of the HLADQB1 has been shown in POTS patients ${ }^{[18]}$. In our study, we found that the frequency of POTS increased significantly in the coexistence of HLADQ2 and HLADQ8 when compared to the presence of the only HLADQ2. This finding supports the idea that POTS has an autoimmune origin.

\section{Conclusion}

In our study, increased incidence of POTS with high AntiTg IgA levels and with the coexistence of HLADQ2 and DQ8 supports the idea of autoimmune origin of the POTS. In the presence of orthostatic symptoms in children with celiac disease, POTS should be considered and cardiologic evaluation of the patients should be performed.

Ethics Committee Approval: This study was approved by the ethics committee of Ümraniye Training and Research Hospital.

Peer-review: Externally peer-reviewed.

Authorship Contributions: Concept: E.E., E.P.; Design: E.E.; Data Collection or Processing: E.P.; Analysis or Interpretation: E.E.; Literature Search: E.P.; Writing: E.E., E.P.

Conflict of Interest: None declared.

Financial Disclosure: The authors declared that this study received no financial support.

\section{References}

1. Nardecchia S, Auricchio R, Discepolo V, Troncone R. Extra-Intestinal Manifestations of Coeliac Disease in Children: Clinical Features and Mechanisms. Front Pediatr 2019;7:56. [CrossRef]

2. Dalgıç B, Sarı S, Özcan B, Baştürk B, Ensari A, Eğritaş Ö, et al. The evaluation of factors and symptoms related to celiac disease in Turkish children. Türk Ped Arş 2011;46:323-30. [CrossRef]

3. Laurikka P, Nurminen S, Kivelä L, Kurppa K. Extraintestinal Manifestations of Celiac Disease: Early Detection for Better Long-Term Outcomes. Nutrients 2018;10:1015. [CrossRef]

4. Popp A, Mäki M. Changing Pattern of Childhood Celiac Disease Epidemiology: Contributing Factors. Front Pediatr 2019;7:357.

5. Barbato M, Curione M, Amato S, Carbone J, Briani C, Pannone $\mathrm{V}$, et al. Autonomic imbalance in celiac children. Minerva Pediatr 2010;62:333-8. 
6. Freeman R, Wieling W, Axelrod FB, Benditt DG, Benarroch E, Biaggioni $I$, et al. Consensus statement on the definition of orthostatic hypotension, neurally mediated syncope and the postural tachycardia syndrome. Clin Auton Res 2011;21:6972. [CrossRef]

7. Sheldon RS, Grubb BP 2nd, Olshansky B, Shen WK, Calkins H, Brignole M, et al. 2015 heart rhythm society expert consensus statement on the diagnosis and treatment of postural tachycardia syndrome, inappropriate sinus tachycardia, and vasovagal syncope. Heart Rhythm 2015;12:e41-63. [CrossRef]

8. Thieben MJ, Sandroni P, Sletten DM, Benrud-Larson LM, Fealey $\mathrm{RD}$, Vernino $\mathrm{S}$, et al. Postural orthostatic tachycardia syndrome: the Mayo clinic experience. Mayo Clin Proc 2007;82:308-13.

9. Singer W, Sletten DM, Opfer-Gehrking TL, Brands CK, Fischer PR, Low PA. Postural tachycardia in children and adolescents: what is abnormal? J Pediatr 2012;160:222-6. [CrossRef]

10. Hadjivassiliou M, Grünewald RA, Davies-Jones GA. Gluten sensitivity as a neurological illness. J Neurol Neurosurg Psychiatry 2002;72:560-3. [CrossRef]

11. Gibbons $\mathrm{CH}$, Freeman R. Autonomic neuropathy and coeliac disease. J Neurol Neurosurg Psychiatry 2005;76:579-81. [CrossRef]

12. Huang RJ, Chun CL, Friday K, Triadafilopoulos G. Manometric abnormalities in the postural orthostatic tachycardia syndrome: a case series. Dig Dis Sci 2013;58:3207-11. [CrossRef]

13. Penny HA, Aziz I, Ferrar M, Atkinson J, Hoggard N, Hadjivassiliou $M$, et al. Is there a relationship between gluten sensitivity and postural tachycardia syndrome? Eur J Gastroenterol Hepatol 2016;28:1383-7. [CrossRef]

14. Li H, Yu X, Liles C, Khan M, Vanderlinde-Wood M, Galloway A, et al. Autoimmune basis for postural tachycardia syndrome. J Am Heart Assoc 2014;3:e000755. [CrossRef]

15. Singer W, Klein CJ, Low PA, Lennon VA. Autoantibodies in the postural tachycardia syndrome. 25th International Symposium on the Autonomic Nervous System Abstracts. Clin Auton Res 2014;24:199-243. [CrossRef]

16. Blitshteyn S. Autoimmune markers and autoimmune disorders in patients with postural tachycardia syndrome (POTS). Lupus 2015;24:1364-9. [CrossRef]

17. Fedorowski A, Li H, Yu X, Koelsch KA, Harris VM, Liles C, et al. Antiadrenergic autoimmunity in postural tachycardia syndrome. Europace 2017;19:1211-9. [CrossRef]

18. Shin YW, Moon J, Kim TJ, Kim DY, Chang H, Jun JS, et al. Human leukocyte antigen associations in postural tachycardia syndrome. Ann Clin Transl Neurol 2019;6:962-7. [CrossRef] 